\title{
Reference Values and Influencing Factors Analysis for Current Perception Threshold Testing Based on Study of 166 Healthy Chinese
}

\author{
Hexiang Yin, Mingsheng Liu, Yicheng Zhu and Liying Cui* \\ Department of Neurology, Peking Union Medical College Hospital, Chinese Academy of Medical Sciences, Beijing, China
}

\section{OPEN ACCESS}

Edited by:

Rufin VanRullen,

Université Toulouse III Paul Sabatier,

France

Reviewed by:

loan Andrei Veresiu,

Iuliu Haţieganu University of Medicine and Pharmacy, Romania

Lu Zhang,

Georgia Institute of Technology,

United States

*Correspondence:

Liying Cui

pumchcuily@sina.com

Specialty section: This article was submitted to

Perception Science,

a section of the journal

Frontiers in Neuroscience

Received: 25 September 2017 Accepted: 10 January 2018

Published: 26 January 2018

Citation:

Yin H, Liu M, Zhu Y and Cui L (2018) Reference Values and Influencing

Factors Analysis for Current

Perception Threshold Testing Based on Study of 166 Healthy Chinese.

Front. Neurosci. 12:14. doi: 10.3389/fnins.2018.00014
The current perception threshold (CPT) is a device which can evaluate different sensory fibers quantitatively through different frequencies of the electrical stimulus and has been applied in clinical practice. Previous studies have implied that CPT values may be affected by age, gender, and other factors, yet not conclusively. The objective of our study is to clarify the influencing factors of CPT values and establish a reference value range. Twenty healthy volunteers recruited publicly and 146 subjects who took CPT tests in the census of the national project cardiovascular and cerebrovascular diseases in rural areas of China from 2013 to 2015 were analyzed. Past medical history and demographic characteristics such as age, gender, and occupation were collected. Each subject was tested on the left index finger (or back of the left hand) and the right hallux. CPT values of 2000, 250, and $5 \mathrm{~Hz}$ on both sites were recorded for statistical analysis. Gender differences were shown at $2000 \mathrm{~Hz}$ CPT on the back of the hand and hallux ( $p<0.01$ ), and male subjects had a higher CPT. Age had a positive correlation with $250 \mathrm{~Hz}$ CPT on the index finger $(p<0.05$, $r=1.5), 2000 \mathrm{~Hz}$ CPT on the back of the hand $(p<0.001, r=1.2)$ and index finger $(p<0.05, r=2.5)$. Manual workers had a higher $250 \mathrm{~Hz}$ CPT on the hallux than mental workers $(p<0.01)$. After investigating the impact of different factors on CPT testing, we established the reference value for subjects with different characteristics.

Keywords: sensory nerve fibers, current perception threshold, neuroselective, reference value, age effects, gender effects, occupational effects

\section{INTRODUCTION}

Cutaneous sensory nerve fibers are typically classified into three varieties according to their cross sectional diameters. These classifications are the larger myelinated A-beta $(\beta)$ fibers $(5-15 \mu \mathrm{m}$ diameter), lightly myelinated A-delta $(\delta)$ fibers (1-4 $\mu \mathrm{m}$ diameter) and the unmyelinated $\mathrm{C}$ fibers (0.5-1.5 $\mu \mathrm{m}$ diameter). A- $\beta$ fibers conduct the senses of touch, pressure, and vibration, while both A- $\delta$ fibers and $C$ fibers conducting the senses of pain and temperature, and $C$ fibers also serve as post-sympathetic fibers (McGlone and Reilly, 2010). Evaluation of the sensory nerve fiber's function plays a vital role in the diagnosis and follow-up of certain diseases involving the sensory conducting pathways. Different from classical examination tools, such as cotton, pin, and tuning fork, or neurophysiological methods, such as sensory nerve conduction velocity (SCV), sensory nerve action potential (SNAP), and somatosensory evoked potential (SEP), the current perception threshold (CPT) device can document the functioning of the sensory nerve fibers in a quantitative manner and achieve differential neuro-excitatory effects of the sensory fibers depending on the 
frequency of stimuli (Katims et al., 1986a,b; Baquis et al., 1999). Evidence suggested that stimuli of 2000, 250, and $5 \mathrm{~Hz}$ reflected the functions of A- $\beta$, A- $\delta$, C fibers, respectively (Félix et al., 2009; Neurotron, 2010). The definition of CPT on certain body parts is the lowest electric stimuli intensity which can be perceived consistantly, therefore the test measures are recorded as current intensity values ranging from 0.01 to $9.99 \mathrm{~mA}$. Results of CPT below the normal range are suspected as hyperesthesia, while those of CPT above the normal range imply hypoesthesia.

The CPT device has been applied in the diagnosis and evaluation of many clinical conditions, of which diabetic neuropathy is the most common (Rendell et al., 1989; Katims et al., 1991; Rendell and Bamisedun, 1992; Lee et al., 1997; Ro et al., 1999; Menkes et al., 2000; Kurozawa and Nasu, 2001; Oishi et al., 2002; Takekuma et al., 2002; Cui et al., 2003; Prendergast et al., 2004; Lander et al., 2007; Putz et al., 2009; Nather et al., 2011; Griffith et al., 2014). However, more than one study has found differences between the reference values of the research subjects and those provided by the manufacturer (Galvão Mde et al., 2005; Quaghebeur and Wyndaele, 2014), and the influence of factors such as age and gender on CPT values has not been illustrated consistently among various studies (Evans et al., 1992; Takekuma et al., 2000; Tseng et al., 2002; Seong et al., 2009). Therefore, the objective of our study was to explore CPT distribution properties of Chinese subjects and to investigate different influencing factors of CPT. Furthermore, we aimed to establish reference value ranges suitable for subjects with different clinical characteristics.

\section{MATERIALS AND METHODS}

\section{Subjects}

The healthy subjects were recruited through two different approaches. The majority came from the census of the national project cardiovascular and cerebrovascular diseases in rural areas of China from 2013 to 2015, and the others were recruited publicly for CPT testing. The inclusion criteria were for individuals having no history or complaints of sensory dysfunction and having a normal physical examination. Exclusion criteria were as follows: a history of diabetes mellitus (DM), consumption of alcohol, central nervous system diseases, cervical or lumbar spondylosis, malignant tumors, usage of vibratory tools, electrical application implants (such as pace maker), and the presence of skin lesions at the testing site.

This study was performed in compliance with the Code of Ethics of the World Medical Association (Declaration of Helsinki) and was approved by the ethics committee of Peking Union Medical College Hospital. All subjects participated voluntarily after being provided information about the testing procedures. Written informed consent was obtained from each subject prior to participation.

\section{Data Collection}

\section{Clinical Data}

Before CPT testing, all of the subjects underwent a medical history investigation and physical examination. Information as follows was collected: name, gender, age, occupation, past medical history, personal history including usage of medications and history of contact with toxins.

\section{CPT Testing}

CPT tests were performed with a Neurometer ${ }^{\circledR}$ (Neurotron, Inc., Baltimore, MD, USA) which measures the neuroselective CPTs. The testing sites were selected as either the left index finger or the back of the hand (C7 dermatome) and the right hallux (L4/5 dermatome), and the placement of the electrode is shown in Figure 1. Automatic double-blinded testing was applied. Subjects sat in a quiet room with a comfortable environmental temperature and lighting, and were informed about the procedure carefully beforehand to ensure understanding and better cooperation during the following test. The skin at the testing site was prepared with a skin prep paste and a hypoallergenic electrode gel was applied to the electrodes before placement. The current levels of 2000, 250, and $5 \mathrm{~Hz}$ CPTs were tested in turn at each site. The total test time for each subject was no more than $15 \mathrm{~min}$.

\section{Statistical Analysis}

The categorical variables were recorded as frequency and percentage. Distribution was evaluated with a normality test (One-Sample Kolmogorov-Smirnov test). Normally distributed variables were presented as the mean (standard deviation) and non-normally distributed variables as the median (interquartile range). Differences between the groups were analyzed with independent sampled $t$-tests for two groups or ANOVA for more than two groups with continuous data and chi square tests for categorical data. Correlation analysis: Pearson analysis was applied to normal distribution while Spearman analysis was applied to non-normal distribution. Clinical factors influencing CPT testing results were accessed by logistic regression analysis. A $p$-value of 0.05 or less was considered statistically significant. Analyses were conducted using SPSS 20.0 (IBM Corp., Armonk, NY, USA).

\section{RESULTS}

\section{Demographic Data}

One hundred and sixty-six healthy subjects were included, and the age and gender distribution is shown in Table 1. There is no significant difference in age distribution between the male and

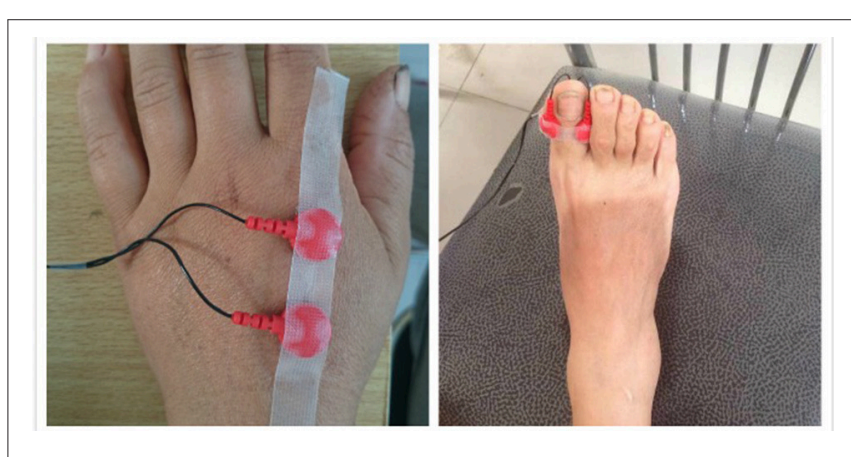

FIGURE 1 | Testing site and the placement of the electrode. 
female groups $(p>0.05)$. Eight subjects' occupations were not available, with the rest consisting of 107 manual workers and 51 mental workers.

\section{CPT Data}

\section{Distribution of CPT Data}

CPT values of different testing sites are shown in Table 2. A normality test showed all values are normally distributed.

\section{Comparison between Left and Right Sides}

Of the participants, 34 subjects completed CPT testing on both sides, and the comparisons of the results from both sides at different testing sites are shown in Table 3. There is no significant difference between CPT values obtained from the left and right side, so unilateral data is qualified for formulating the reference values.

\section{Comparison of Testing Sites}

The mean CPT values of the three frequencies at each testing site are shown in Figure 2, and further comparison between CPT values of the same frequency at different testing site are shown in Figures 3, 4, separately. The CPT value for the back of the hand was generally lower than that of the hallux $(p<0.001)$, and a lower CPT value was obtained at the index finger than the hallux under a stimulus of $2000 \mathrm{~Hz}(p<0.01)$.

\section{Influencing Factor Analysis}

Multivariate logistic regression analysis of influencing factors is shown in Table 4. Gender, age and occupation show effects

TABLE 1 | Age and gender distribution of the 166 subjects.

\begin{tabular}{lcc}
\hline & $\boldsymbol{n}$ & Mean $\pm \boldsymbol{S D}$, age, $\mathbf{y}$ \\
\hline Male & 37 & $49.0 \pm 13.6$ \\
Female & 129 & $52.2 \pm 10.0$ \\
\hline
\end{tabular}

TABLE 2 | CPT values of different testing sites [Mean $\pm S D$ (range), unit: $10 \mu \mathrm{A}]$.

\begin{tabular}{lcccc}
\hline & $\boldsymbol{n}$ & $\mathbf{2 0 0 0} \mathbf{~ H z}$ & $\mathbf{2 5 0 ~} \mathbf{~ z}$ & $\mathbf{5 ~ H z}$ \\
\hline Index finger & \multirow{2}{*}{35} & $\begin{array}{c}226.8 \pm 63.7 \\
(95-396)\end{array}$ & $\begin{array}{c}100.0 \pm 34.8 \\
(40-192)\end{array}$ & $\begin{array}{c}57.2 \pm 21.8 \\
(13-90)\end{array}$ \\
Hand back & \multirow{2}{*}{131} & $\begin{array}{c}136.8 \pm 37.8 \\
(46-250)\end{array}$ & $\begin{array}{c}39.8 \pm 11.7 \\
(19-62)\end{array}$ & $\begin{array}{c}19.9 \pm 8.0 \\
(5-41)\end{array}$ \\
Hallux & & $287.7 \pm 72.1$ & $124.0 \pm 47.0$ & $71.4 \pm 34.9$ \\
& \multirow{2}{*}{166} & $(95-492)$ & $(10-247)$ & $(7-164)$
\end{tabular}

TABLE 3 | Comparison between values from left and right side $(n=34)$.

\begin{tabular}{lcc}
\hline Testing site & Frequency $\mathbf{( H z )}$ & $\boldsymbol{P}$-value \\
\hline Hand & 2000 & 0.489 \\
& 250 & 0.508 \\
& 5 & 0.360 \\
\hline Foot & 2000 & 0.415 \\
& 250 & 0.266 \\
& 5 & 0.871
\end{tabular}

on certain frequencies at different testing sites, respectively. Gender differences were shown at $2000 \mathrm{~Hz}$ CPT on the back of the hand and the hallux $(p<0.01)$, and male subjects had a higher CPT. Age had a positive correlation with $250 \mathrm{~Hz} \mathrm{CPT}$ on the index finger $(p<0.05, r=1.5)$, $2000 \mathrm{~Hz}$ CPT on the back of the hand $(p<0.001, r=1.2)$ and the index finger $(p<0.05, r=2.5)$. Manual workers had higher $250 \mathrm{~Hz}$ CPT on the hallux than mental workers $(p<0.01)$.

\section{Reference Values of CPT Testing}

Based the results of influencing factor analysis, the reference values of CPT testing for the three frequencies at different sites were established in Table 5. The reference values of $2000 \mathrm{~Hz}$ CPT on the hallux were divided by gender, and those of $250 \mathrm{~Hz}$ CPT on the hallux were divided by occupation. The reference values of 2000 and $250 \mathrm{~Hz}$ CPT on the index finger were established according to age, while those of $2000 \mathrm{~Hz}$ CPT on the index finger were divided by age and gender.

\section{DISCUSSION}

\section{Distribution Characteristics of Normal CPT}

Our study shows the distribution characteristics of normal CPT values, which are consistent with previous studies (Katims et al., 1986b; Seong et al., 2009; Neurotron, 2010). The CPT value for the back of the hand was generally lower than that of the hallux $(p<0.001)$, and a lower CPT value was obtained at the index finger than the hallux under a stimulus of $2000 \mathrm{~Hz}(p<0.01)$. This could be explained by differences in the density of sensory nerve fibers on different parts of the body (Stevens and Choo, 1996; Johansson et al., 1999; McGlone and Reilly, 2010). Nerve fiber density for human skin appeared to decrease from the trunk to the distal parts of the body, and the intraepidermal nerve fiber density of the distal leg was lower than that of the distal forearm (Besné et al., 2002; Chang et al., 2004).

\section{Gender Effects}

Compared with women, men in this study tended to have higher CPT values for the back of the hand and hallux under a stimulus

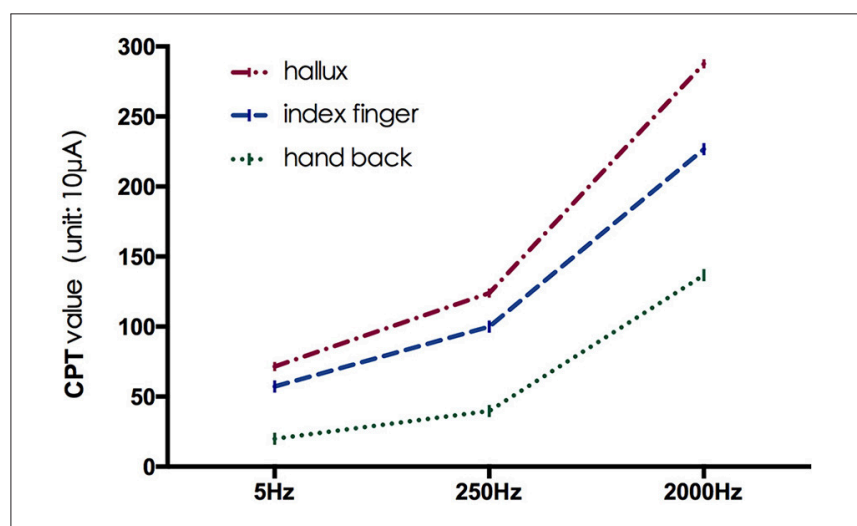

FIGURE 2 | The mean CPT values of the three frequencies at each testing site. 


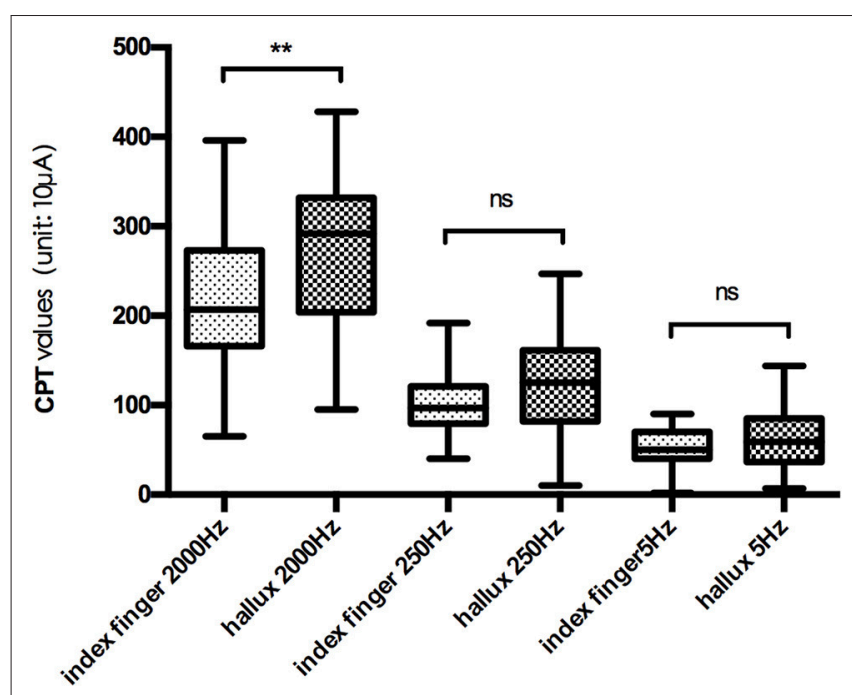

FIGURE 3 | Comparison between CPT values at index finger and hallux. ${ }^{* *} p<$ $0.01 ;$ ns, no significance.

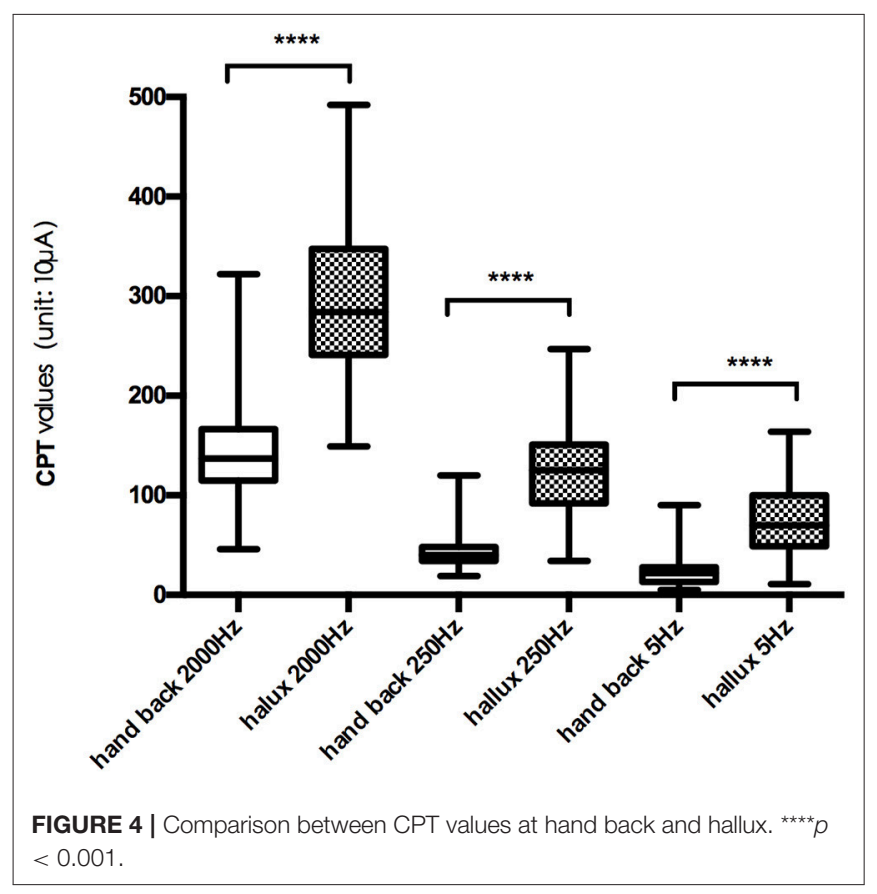

of $2000 \mathrm{~Hz}$. Similarly, Seong et al. (2009) reported gender differences for normal CPT values only appeared in the $2000 \mathrm{~Hz}$ stimulus group $(p<0.01)$, and males had a higher perception threshold. Females were reported to have higher myelinated nerve fiber densities than males (Horowitz and Krarup, 1992), which partly gives an explanation on the effects of gender on CPT values under a stimulus of $2000 \mathrm{~Hz}$.

We did not find gender differences at the testing site for the index finger, which is accordant with reports from Quaghebeur et al. (Quaghebeur and Wyndaele, 2014) and Galvão Mde et al. (2005). However, Takekuma et al. revealed gender effects on CPT values for the index finger under stimuli of
250 and $5 \mathrm{~Hz}$ in a community-dwelling of 1,000 Japanese, of which males had higher CPT values (Takekuma et al., 2000). The divergence of different studies may result from the sample differences. The number of our subjects was 35 , while that of the other two studies were 41 and 101, respectively. Furthermore, there were racial differences found among these studies. Research of intraepidermal nerve fiber (IENF) density in the distal leg was discovered with a significant lower density in men (Goransson et al., 2004), and the majority of IENF was $\mathrm{A} \delta$ and $\mathrm{C}$ fibers, whose functions could be reflected by CPT values under stimuli of 250 and $5 \mathrm{~Hz}$. Therefore, there are possible gender effects on CPT values under stimuli of 250 and $5 \mathrm{~Hz}$. Whereas, there were no gender differences of IENF shown in other research (McArthur et al., 1998). Moreover, studies of painful sensory neuropathy presented a poor relationship between nerve fiber density and measurements of quantitative sensory testing (Holland et al., 1997; Periquet et al., 1999).

A consistent conclusion has not been drawn for gender effects on CPT values under different stimuli, and studies with larger samples are needed for further exploration.

\section{Age Effects}

Age effects were shown in CPT values found at the index finger under stimuli of 250 and $2000 \mathrm{~Hz}(p<0.05)$, and the back of the hand under a stimulus of $2000 \mathrm{~Hz}(p<0.01)$. Age had a positive correlation with the CPT values referred above. Similar results were revealed in previous studies (Katims et al., 1986b; Takekuma et al., 2000; Costantini et al., 2006; Seong et al., 2009), some of which also found that age had a negative correlation with $\mathrm{CPT}$ values under a stimulus of $5 \mathrm{~Hz}$. One study showed no age effects on CPT values in normal subjects or patients of peripheral neuropathy (Evans et al., 1992), while Tseng et al. concluded that age had a positive correlation with CPT values under each frequency of stimuli (Tseng et al., 2002).

The majority of the previous studies report that age has a positive correlation with CPT values under a stimulus $2000 \mathrm{~Hz}$, which is consistent with the phenomenon that sensitivity to vibration and touch decreases in the elderly. The underlying mechanism may lie in age effects on each part of the sensory conducting pathways. It has been proven that both the number of mechanoreceptors and density of nerve fibers in the skin decrease with the increase of age (Cerimele et al., 1990; Gescheider et al., 1994; Besné et al., 2002; Chang et al., 2004; Goransson et al., 2004; Aydog et al., 2006; Vega et al., 2009). Moreover, age-related changes of skin structures such as the soft tissue and the vascular system, which are required to ensure efferent function of the afferent nerve fibers in the skin, play a role in the conduction of sensory information (Bailey, 2001; Farage et al., 2007; Wu et al., 2011; Decorps et al., 2014). A loss of thick myelinated nerve fibers was found with aging, while thin myelinated and unmyelinated nerve fibers were retained (Sato et al., 1985; Drac et al., 1991; Kanda et al., 1991; Verdú et al., 1996; Nakayama et al., 1998; Moriyama et al., 2007). Apart from a loss in quantity, the structural destruction of thick myelinated nerve fibers can exacerbate recession of vibratory senses. It has been proven that the nerve conduction velocity decreases with aging, accompanied 
TABLE 4 | Multivariate logistic regression analysis of influencing factors ( $p$-value).

\begin{tabular}{|c|c|c|c|c|c|c|c|c|c|}
\hline \multirow[b]{2}{*}{ Factors } & \multicolumn{3}{|c|}{ Index finger } & \multicolumn{3}{|c|}{ Hand back } & \multicolumn{3}{|c|}{ Hallux } \\
\hline & $2000 \mathrm{~Hz}$ & $250 \mathrm{~Hz}$ & $5 \mathrm{~Hz}$ & $2000 \mathrm{~Hz}$ & $250 \mathrm{~Hz}$ & $5 \mathrm{~Hz}$ & $2000 \mathrm{~Hz}$ & $250 \mathrm{~Hz}$ & $5 \mathrm{~Hz}$ \\
\hline Gender & 0.500 & 0.756 & 0.682 & 0.003 & 0.612 & 0.704 & 0.009 & 0.721 & 0.427 \\
\hline Age & $0.038(r=2.5)$ & $0.023(r=1.5)$ & 0.862 & $0.000(r=1.2)$ & 0.214 & 0.272 & 0.061 & 0.928 & 0.687 \\
\hline Occupation & 0.785 & 0.514 & 0.986 & 0.100 & 0.100 & 0.363 & 0.072 & 0.007 & 0.426 \\
\hline
\end{tabular}

$r=$ correlation coefficient.

TABLE 5 | Reference values of CPT testing (unit: $10 \mu \mathrm{A}$ ).

\begin{tabular}{|c|c|c|c|c|c|c|}
\hline & & $\begin{array}{r}\text { Gender/oc } \\
\text { (yea }\end{array}$ & on/age & $\begin{array}{l}\text { Lower } \\
95 \% \mathrm{Cl}\end{array}$ & Mean & $\begin{array}{l}\text { Upper } \\
95 \% \text { CI }\end{array}$ \\
\hline \multirow{5}{*}{$\begin{array}{l}\text { Index finger } \\
(C 7, n=35)\end{array}$} & \multirow[t]{2}{*}{$2000 \mathrm{~Hz}$} & \multicolumn{2}{|c|}{$\leq 50$} & 93.2 & 209.2 & 325.2 \\
\hline & & \multicolumn{2}{|c|}{$>50$} & 111.2 & 239.2 & 367.2 \\
\hline & \multirow[t]{2}{*}{$250 \mathrm{~Hz}$} & \multicolumn{2}{|c|}{$\leq 50$} & 39.2 & 87.9 & 136.7 \\
\hline & & \multicolumn{2}{|c|}{$>50$} & 32.5 & 108.1 & 183.6 \\
\hline & $5 \mathrm{~Hz}$ & \multicolumn{2}{|c|}{-} & 14.5 & 57.2 & 99.9 \\
\hline \multirow{6}{*}{$\begin{array}{l}\text { Hand back } \\
(C 7, n=131)\end{array}$} & \multirow[t]{4}{*}{$2000 \mathrm{~Hz}$} & \multirow[t]{2}{*}{ Male } & $\leq 50$ & 65.0 & 137.3 & 209.6 \\
\hline & & & $>50$ & 112.8 & 157.9 & 203.0 \\
\hline & & \multirow[t]{2}{*}{ Female } & $\leq 50$ & 37.7 & 121.0 & 204.3 \\
\hline & & & $>50$ & 75.0 & 142.0 & 209.0 \\
\hline & $250 \mathrm{~Hz}$ & \multicolumn{2}{|c|}{-} & 16.9 & 39.8 & 62.7 \\
\hline & $5 \mathrm{~Hz}$ & \multicolumn{2}{|c|}{-} & 4.2 & 19.9 & 35.6 \\
\hline \multirow{5}{*}{$\begin{array}{l}\text { Hallux (L4/5, } \\
n=166)\end{array}$} & $2000 \mathrm{~Hz}$ & \multicolumn{2}{|c|}{ Male } & 166.0 & 304.4 & 442.8 \\
\hline & & \multicolumn{2}{|c|}{ Female } & 141.8 & 282.9 & 424.0 \\
\hline & $250 \mathrm{~Hz}$ & \multicolumn{2}{|c|}{ Manual workers } & 36.2 & 130.1 & 224.0 \\
\hline & & \multicolumn{2}{|c|}{ Mental workers } & 25.2 & 107.5 & 189.8 \\
\hline & $5 \mathrm{~Hz}$ & \multicolumn{2}{|c|}{-} & 3.0 & 71.4 & 139.8 \\
\hline
\end{tabular}

by a declining amplitude of SNAP and a prolonged latency time of SEP (Dorfman and Bosley, 1979; Bouche et al., 1993). Furthermore, dramatic age-related differences in the processing of a simple tactile stimulus on the somatosensory network has been revealed (Brodoehl et al., 2013). All of the above factors may lead to an increasing perception threshold in the elderly.

\section{Occupational Effects}

In a different approach from the previous normal value studies, we investigate the effects of occupations on CPT values and found that manual workers have higher CPT values at the hallux under stimuli of $250 \mathrm{~Hz}$ than that of mental workers $(p<0.01)$. The possible explanation of occupational effects on CPT is the differences in history of contact with risk factors between manual and mental workers. The risk factors which have been reported to be related with changes in perception thresholds, including repetitive movements of arms and hands, and long-term exposure to chemicals, heavy metals and pesticides (Bleecker et al., 2005; Lander et al., 2007; Lubis et al., 2008). The manual workers in our study consisted mainly of farmers, production and transport laborers, and household laborers. The occupation effects are only shown in CPT value of the hallux under $250 \mathrm{~Hz}$, which implies sensory nerve fiber impairment of the distal leg is more severe than the upper extremities and different types of sensory nerve fibers are damaged to a different extent. Without a doubt, more studies of the occupational effects on CPT values are needed to prove its validity.

\section{Limitations}

This was a single source of study in which the majority of the subjects come from countryside of China and females predominate in the study, therefore the representativeness of the study sample is unclear. In addition, though reference values for different conditions have been established based on the impact of subject's characteristics, its sensitivity and specificity for screening and diagnosis of peripheral sensory neuropathy remain to be verified.

\section{CONCLUSIONS}

As a neurophysiological tool for quantitative assessment of sensory nerve functions, CPT can selectively test different subtypes of sensory nerve fibers in a quick and non-invasive way. The impact of the different factors on the CPT tests will be revealed as follows. Gender differences were shown at $2000 \mathrm{~Hz}$ CPT on the back of the hand and the hallux $(p<0.01)$, and male subjects had a higher CPT. Age had a positive correlation with $250 \mathrm{~Hz} \mathrm{CPT}$ on the index finger $(p<0.05, r=1.5), 2000 \mathrm{~Hz}$ CPT on the back of the hand $(p<0.001, r=1.2)$ and the index finger $(p<0.05, r=2.5)$. Manual workers had higher $250 \mathrm{~Hz}$ CPT on the hallux than mental workers $(p<0.01)$. Reference values for different subject characteristics based on the influencing factor analysis were established.

\section{AUTHOR CONTRIBUTIONS}

HY: conducted the literature search, collected all the data, performed all the data analysis, data interpretation, and wrote the first draft version of the manuscript; $\mathrm{ML}$ and YZ: designed the study and standardized testing protocol; ML: supervised analyses, interpreted the data, and reviewed the draft version of the manuscript; LC: designed the study, interpreted the data and reviewed the draft version of 
the manuscript; All authors read and approved the final manuscript.

\section{FUNDING}

The study was supported by National Key Technology R\&D Program in the 12th five-year Plan of China (No.

\section{REFERENCES}

Aydog, S. T., Korkusuz, P., Doral, M. N., Tetik, O., and Demirel, H. A. (2006). Decrease in the numbers of mechanoreceptors in rabbit ACL: the effects of ageing. Knee Surgery Sports Traumatol. Arthrosc. 14, 325-329. doi: 10.1007/s00167-005-0673-2

Bailey, A. J. (2001). Molecular mechanisms of ageing in connective tissues. Mech. Ageing Dev. 122, 735-755. doi: 10.1016/S0047-6374(01)00225-1

Baquis, G. D., Brown, W. F., Capell, J. T., Chaudhry, V., Cros, D., Drexinger, B. R., et al. (1999). Technology review: the neurometer (R) current perception threshold (CPT). Muscle Nerve 22, 523-531. doi: 10.1002/(SICI) 1097-4598(199904)22:4<523::AID-MUS16>3.0.CO;2-1

Besné, I., Descombes, C., and Breton, L. (2002). Effect of age and anatomical site on density of sensory innervation in human epidermis. Arch. Dermatol. 138, 1445-1450. doi: 10.1001/archderm.138.11.1445

Bleecker, M. L., Ford, D. P., Vaughan, C. G., Lindgren, K. N., Tiburzi, M. J., and Walsh, K. S. (2005). Effect of lead exposure and ergonomic stressors on peripheral nerve function. Environ. Health Perspect. 113, 1730-1734. doi: $10.1289 /$ ehp. 8106

Bouche, P., Cattelin, F., Saint-Jean, O., Leger, J. M., Queslati, S., Guez, D., et al. (1993). Clinical and electrophysiological study of the peripheral nervoussystem in the elderly. J. Neurol. 240, 263-268. doi: 10.1007/BF00838158

Brodoehl, S., Klingner, C., Stieglitz, K., and Witte, O. W. (2013). Age-related changes in the somatosensory processing of tactile stimulation-an fMRI study. Behav. Brain Res. 238, 259-264. doi: 10.1016/j.bbr.2012.10.038

Cerimele, D., Celleno, L., and Serri, F. (1990). Physiological-changes in aging skin. Br. J. Dermatol. 122, 13-20. doi: 10.1111/j.1365-2133.1990.tb16120.x

Chang, Y. C., Lin, W. M., and Hsieh, S. T. (2004). Effects of aging on human skin innervation. Neuroreport 15, 149-153. doi: 10.1097/00001756-200401190-00029

Costantini, M., Tunks, K., Wyatt, C., Zettel, H., and MacDermid, J. C. (2006). Age and upper limb tension testing affects current perception thresholds. J. Hand Ther. 19, 307-316; quiz 17. doi: 10.1197/j.jht.2006.04.015

Cui, L., Zhu, P., Fu, H., and Starr, A. (2003). Current perception threshold (CPT) in Syringomyelia. J. Chin. Neurol. 36, 444-447. doi: 10.3760/j.issn:1006-7876.2003.06.014

Decorps, J., Saumet, J. L., Sommer, P., Sigaudo-Roussel, D., and Fromy, B. (2014). Effect of ageing on tactile transduction processes. Ageing Res. Rev. 13, 90-99. doi: 10.1016/j.arr.2013.12.003

Dorfman, L. J., and Bosley, T. M. (1979). Age-related changes in peripheral and central nerve conduction in man. Neurology 29, 38-44. doi: 10.1212/WNL.29.1.38

Drac, H., Babiuch, M., and Wisniewska, W. (1991). Morphological and biochemical changes in peripheral nerves with aging. Neuropatol. Pol. 29, 49-67.

Evans, E. R., Rendell, M. S., Bartek, J. P., Bamisedun, O., Connor, S., and Giitter, M. (1992). Current perception thresholds in ageing. Age Ageing 21, 273-279. doi: 10.1093/ageing/21.4.273

Farage, M. A., Miller, K. W., Elsner, P., and Maibach, H. I. (2007). Structural characteristics of the aging skin: a review. Cutan. Ocul. Toxicol. 26, 343-357. doi: 10.1080/15569520701622951

Félix, E. P., Giuliano, L. M., Tierra-Criollo, C. J., Gronich, G., Braga, N. I., Peres, C. A., et al. (2009). Sensations and reaction times evoked by electrical sinusoidal stimulation. Neurophysiol. Clin. 39, 283-290. doi: 10.1016/j.neucli.2009.10.001

Galvão Mde, L., Manzano, G. M., Braga, N., and Nobrega, J. A. (2005). Determination of electric current perception threshold in
2012BAJ18B04-3) and National High Technology Research \& Development Program of China (No. 2015AA020506).

\section{ACKNOWLEDGMENTS}

We are indebted to the subjects who participated in the study for their consent and cooperation.

a sample of normal volunteers. Arq. Neuropsiquiatr. 63, 289-293. doi: 10.1590/S0004-282X2005000200016

Gescheider, G. A., Bolanowski, S. J., Hall, K. L., Hoffman, K. E., and Verrillo, R. T. (1994). The effects of aging on information-processing channels in the sense of Touch.1. Absolute Sensitivity. Somatos. Motor Res. 11, 345-357. doi: 10.3109/08990229409028878

Goransson, L. G., Mellgren, S. I., Lindal, S., and Omdal, R. (2004). The effect of age and gender on epidermal nerve fibre density. Neurology 62, 774-777. doi: 10.1212/01.WNL.0000113732.41127.8F

Griffith, K. A., Couture, D. J., Zhu, S., Pandya, N., Johantgen, M. E., Cavaletti, G., et al. (2014). Evaluation of chemotherapy-induced peripheral neuropathy using current perception threshold and clinical evaluations. Support. Care Cancer 22, 1161-1169. doi: 10.1007/s00520-013-2068-0

Holland, N. R., Stocks, A., Hauer, P., Cornblath, D. R., Griffin, J. W., and McArthur, J. C. (1997). Intraepidermal nerve fibre density in patients with painful sensory neuropathy. Neurology 48, 708-711. doi: 10.1212/WNL.48.3.708

Horowitz, S. H., and Krarup, C. (1992). Conduction studies of the normal sural nerve. Muscle Nerve 15, 374-383. doi: 10.1002/mus.880150318

Johansson, O., Wang, L., Hilliges, M., and Liang, Y. (1999). Intraepidermal nerves in human skin: PGP 9.5 immunohistochemistry with special reference to the nerve density in skin from different body regions. J. Peripher. Nerv. Syst. 4, 43-52.

Kanda, T., Tsukagoshi, H., Oda, M., Miyamoto, K., and Tanabe, H. (1991). Morphological-changes in unmyelinated nerve-fibres in the sural nerve with age. Brain 114, 585-599. doi: 10.1093/brain/114.1.585

Katims, J. J., Long, D. M., and Ng, L. K. (1986a). Trans-cutaneous nervestimulation - frequency and wave-form specificity in humans. Appl. Neurophysiol. 49, 86-91.

Katims, J. J., Naviasky, E. H., Ng, L. K., Rendell, M., and Bleecker, M. L. (1986b). New screening device for assessment of peripheral neuropathy. J. Occup. Environ. Med. 28, 1219-1221.

Katims, J. J., Patil, A. S., Rendell, M., Rouvelas, P., Sadler, B., Weseley, S. A., et al. (1991). Current perception threshold screening for carpal-tunnel syndrome. Arch. Environ. Health 46, 207-212. doi: 10.1080/00039896.1991.9937449

Kurozawa, Y., and Nasu, Y. (2001). Current perception thresholds in vibration-induced neuropathy. Arch. Environ. Health 56, 254-256. doi: 10.1080/00039890109604450

Lander, L., Lou, W., and House, R. (2007). Nerve conduction studies and current perception thresholds in workers assessed for hand-arm vibration syndrome. Occup. Med. 57, 284-289. doi: 10.1093/occmed/kqm012

Lee, Y., Robinson, M., Wong, N., Chan, E., and Charles, M. A. (1997). The effect of pentoxifylline on current perception thresholds in patients with diabetic sensory neuropathy. J. Diabetes Complicat. 11, 274-278. doi: 10.1016/S1056-8727(96)00077-3

Lubis, S. H., El Sersi, M., Hussein, S. H., Sakian, N. I., Salleh, R., Rafai, J., et al. (2008). A biomarker for exposure to organophosphate and carbamate pesticides. Asia Pac. J. Public Health 20(Suppl.), 162-165.

McArthur, J. C., Stocks, E. A., Hauer, P., Cornblath, D. R., and Griffin, J. W. (1998). Epidermal nerve fibre density - normative reference range and diagnostic efficiency. Arch. Neurol. 55, 1513-1520. doi: 10.1001/archneur.55. 12.1513

McGlone, F., and Reilly, D. (2010). The cutaneous sensory system. Neurosci. Biobehav. Rev. 34, 148-159. doi: 10.1016/j.neubiorev.2009.08.004

Menkes, D. L., Swenson, M. R., and Sander, H. W. (2000). Current perception threshold: an adjunctive test for detection of acquired demyelinating polyneuropathies. Electromyogr. Clin. Neurophysiol. 40, 205-210. 
Moriyama, H., Amano, K., Itoh, M., Shimada, K., and Otsuka, N. (2007). Morphometric aspects of peripheral nerves in adults and the elderly. J. Peripher. Nervous Syst. 12, 205-209. doi: 10.1111/j.1529-8027.2007.00140.x

Nakayama, H., Noda, K., Hotta, H., Ohsawa, H., and Hosoya, Y. (1998). Effects of aging on numbers, sizes and conduction velocities of myelinated and unmyelinated fibres of the pelvic nerve in rats. J. Auton. Nerv. Syst. 69, 148-155. doi: 10.1016/S0165-1838(98)00013-7

Nather, A., Keng Lin, W., Aziz, Z., Hj Ong, C., Mc Feng, B., and Lin, C. (2011). Assessment of sensory neuropathy in patients with diabetic foot problems. Diabet. Foot Ankle 2:6367. doi: 10.3402/dfa.v2i0.6367

Oishi, M., Mochizuki, Y., Suzuki, Y., Ogawa, K., Naganuma, T., Nishijo, Y., et al. (2002). Current perception threshold and sympathetic skin response in diabetic and alcoholic polyneuropathies. Intern. Med. 41, 819-822. doi: 10.2169/internalmedicine.41.819

Periquet, M. I., Novak, V., Collins, M. P., Nagaraja, H. N., Erdem, S., Nash, S. M., et al. (1999). Painful sensory neuropathy - prospective evaluation using skin biopsy. Neurology 53, 1641-1647. doi: 10.1212/WNL.53.8.1641

Prendergast, J. J., Miranda, G., and Sanchez, M. (2004). Improvement of sensory impairment in patients with peripheral neuropathy. Endocr. Pract. 10, 24-30. doi: 10.4158/EP.10.1.24

Putz, Z., Tabak, A. G., Toth, N., Istenes, I., Nemeth, N., Gandhi, R. A., et al. (2009). Noninvasive evaluation of neural impairment in subjects with impaired glucose tolerance. Diabetes Care 32, 181-183. doi: 10.2337/dc08-1406

Quaghebeur, J., and Wyndaele, J. J. (2014). Pudendal and median nerve sensory perception threshold: a comparison between normative studies. Somatosens. Mot. Res. 31, 186-190. doi: 10.3109/08990220.2014.911172

Rendell, M., and Bamisedun, O. (1992). Skin blood flow and current perception in pentoxifylline-treated diabetic neuropathy. Angiology 43, 843-851. doi: 10.1177/000331979204301007

Rendell, M. S., Katims, J. J., Richter, R., and Rowland, F. (1989). A comparison of nerve-conduction velocities and current perception thresholds as correlates of clinical severity of diabetic sensory neuropathy. J. Neurol. Neurosurg. Psychiatry 52, 502-511. doi: 10.1136/jnnp.52.4.502

Ro, L. S., Chen, S. T., Tang, L. M., Hsu, W. C., Chang, H. S., and Huang, C. C. (1999). Current perception threshold testing in Fabry's disease. Muscle Nerve 22, 1531-1537. doi: 10.1002/(SICI)1097-4598(199911)22:11<1531::AID-MUS7>3.0.CO;2-O

Sato, A., Sato, Y., and Suzuki, H. (1985). Aging effects on conduction velocities of myelinated and unmyelinated fibres of peripheral-nerves. Neurosci. Lett. 53, 15-20. doi: 10.1016/0304-3940(85)90090-4
Seong, W. K., Shin, J. B., You, S., Kim, H. S., Song, S. H., and Cho, H. K. (2009). Current perception threshold in different age, sex and body parts. J. Korean EMG Electrodiagn. Med. 11, 92-97. doi: 10.18214/jkaem.2009. 11.2 .92

Neurotron (2010). Neurometer CPT Sensory Nerve Conduction Threshold Current Perception Threshold Test (sNCT/CPT). Neuval Database II-Normative Data (121409). Baltimore, MD: Neurotron.

Stevens, J. C., and Choo, K. K. (1996). Spatial acuity of the body surface over the life span. Somatos. Motor Res. 13, 153-166. doi: 10.3109/08990229609051403

Takekuma, K., Ando, F., Niino, N., and Shimokata, H. (2000). Age and gender differences in skin sensory threshold assessed by current perception in community-dwelling Japanese. J. Epidemiol. 10(Suppl. 1), S33-S38. doi: 10.2188/jea.10.1sup_33

Takekuma, K., Ando, F., Niino, N., and Shimokata, H. (2002). Prevalence of hyperesthesia detected by current perception threshold test in subjects with glucose metabolic impairments in a community. Inter. Med. 41, 1124-1129. doi: 10.2169/internalmedicine.41.1124

Tseng, C. H., Tseng, F. C. P., and Chong, C. K. (2002). Aging and current perception threshold measured by neurometer in normal Taiwanese adults. J. Am. Geriatr. Soc. 50, 2094-2095. doi: 10.1046/j.1532-5415.2002.50627.x

Vega, J. A., Garcia-Suarez, O., Montano, J. A., Pardo, B., and Cobo, J. M. (2009). The meissner and pacinian sensory corpuscles revisited new data from the last decade. Microsc. Res. Tech. 72, 299-309. doi: 10.1002/jemt.20651

Verdú, E., Buti, M., and Navarro, X. (1996). Functional changes of the peripheral nervous system with aging in the mouse. Neurobiol. Aging 17, 73-77. doi: 10.1016/0197-4580(95)02010-1

Wu, M., Fannin, J., Rice, K. M., Wang, B., and Blough, E. R. (2011). Effect of aging on cellular mechanotransduction. Ageing Res. Rev. 10, 1-15. doi: 10.1016/j.arr.2009.11.002

Conflict of Interest Statement: The authors declare that the research was conducted in the absence of any commercial or financial relationships that could be construed as a potential conflict of interest.

Copyright (c) $2018 \mathrm{Yin}, \mathrm{Liu}, \mathrm{Zhu}$ and Cui. This is an open-access article distributed under the terms of the Creative Commons Attribution License (CC BY). The use, distribution or reproduction in other forums is permitted, provided the original author(s) and the copyright owner are credited and that the original publication in this journal is cited, in accordance with accepted academic practice. No use, distribution or reproduction is permitted which does not comply with these terms. 